\title{
Nueva especie de Echeveria (Crassulaceae) del centro-occidente de Michoacán, México
}

\section{New species of Echeveria (Crassulaceae) from central western Michoacán, Mexico}

\author{
Ignacio García Ruiz \\ Centro Interdisciplinario de Investigación para el Desarrollo Integral Regional, Instituto Politécnico Nacional, Unidad Michoacán (CIIDIR-IPN \\ MICHOACÁN). Justo Sierra 28, 59510 Jiquilpan, Michoacán, México. \\ Correspondencia:igarciar@ipn.mx
}

\begin{abstract}
Resumen. Se describe e ilustra Echeveria purhepecha (Crassulaceae) como especie nueva para la ciencia. Por sus características morfológicas, se ubica en la serie Retusae E. Walther. Dentro del grupo, presenta mayor similitud con $E$. fulgens Lem., especialmente con la var. obtusifolia (Rose) Kimnach, de la que difiere por las hojas más cortas, longitud de la inflorescencia menor, menor número de flores por cincino, pedicelo y segmento mayor del cáliz más largos, corola rojo escarlata, y segmentos de la corola oblongo-lanceolados.
\end{abstract}

Palabras clave: Retusae, purhepecha, Nuevo San Juan, Parangaricutiro, Tancítaro.

\begin{abstract}
Echeveria purhepecha (Crassulaceae) is described as a new species and illustrated. According to its morphological features it belongs to series Retusae E. Walther. Within this group, it resembles E. fulgens Lem., especially var. obtusifolia (Rose) Kimnach, from which it differs by its shorter leaves, shorter inflorescence, fewer flowers per cincinnus, longer pedicel and longer major calyx segment, scarlet red corolla and oblong-lanceolate corolla segments.
\end{abstract}

Key words: Retusae, purhepecha, Nuevo San Juan, Parangaricutiro, Tancítaro.

\section{Introducción}

Durante las exploraciones y colectas realizadas para actualizar el listado de la Flora del Parque Nacional Pico de Tancítaro, se colectaron plantas del género Echeveria (Crassulaceae), en la porción oriental de esta montaña, al norte del poblado de Nuevo San Juan Parangaricutiro. Al tratar de asignarle el nombre específico se ubicó en la serie Retusae siguiendo el criterio de Walther (1972), ya que presenta un tallo corto pero evidente, simple o a veces estolonífero, hojas menores de $15 \mathrm{~cm}$ de largo y 7 $\mathrm{cm}$ de ancho, obtusas, retusas, agudas estrechándose hacia la base, escasamente pecioladas, verdes, punteadas de rojo en el borde de la hoja; inflorescencia cima racimosa con 2-4 ramas; pedúnculos generalmente robustos, erecto, con numerosas brácteas, anchas y delgadas; pedicelos evidentes, mayores de $3 \mathrm{~mm}$ de largo; sépalos extendidos; corola de tamaño medio color escarlata y pétalos quillados; sin embargo, algunas características morfológicas, hábitat y distribución geográfica difieren de las especies descritas hasta ahora, además, no se encontró material que coincidiera con la planta en cuestión.

Recibido: 15 abril 2009; aceptado: 16 junio 2010

\section{Descripción}

Echeveria purhepecha I. García, sp. nov. Figs. 1-5.

Tipo: México. Michoacán, municipio Nuevo Parangaricutiro, aproximadamente $0.5 \mathrm{~km}$ al norte de Nuevo San Juan Parangaricutiro. Alt. $1900 \mathrm{~m}$; 19 25' $18^{\prime \prime} \mathrm{N} ; 102^{\circ} 07^{\prime}$ 43"' O. Bosque encino-pino. 29. XI. 1996. I. García y J. A. Machuca 4491 (holotipo IEB, isotipos CIMI, ENCB, MEXU, MICH).

Planta caulibus 8-11 altis. Folia 15-20, in rosulam laxam $8-12 \mathrm{~cm}$ diam spiraliter disposita, laminis carnosis, oblongo-obovatis 2-6.5 cm longis. Inflorescentia 1-3 per rosulam, paniculata, $15-30 \mathrm{~cm}$ (pedunculo incluso), 1-7 floribus, pedicellis 3-8 mm longis. Flores 10-11 mm longi, calyce leviter patenti vel campanulato, sepalis basi connatis; corolla in alabastro conoidea, per anthesin cylindrico-urceolata, segmentis oblongo-lanceolatis 10-11 mm longis, basi scarlatinis vel corallinis; nectariis reniformibus, sulphureis.

Planta herbácea perenne, glabra, suculenta, caulescente; tallo erecto de $8-11 \mathrm{~cm}$ de alto y hasta $1.2 \mathrm{~cm}$ de diámetro cerca de la base con 2-4 ramificaciones, escarioso; hojas, pocas o hasta 15-20, dispuestas en espiral, formando una roseta laxa, ligeramente ascendente, de $8-12 \mathrm{~cm}$ de diámetro, laminas carnosas, color verde oscuro, oblongo- 
obovadas de 2-6.5 $\mathrm{cm}$ de largo y de 1-2.5 $\mathrm{cm}$ de ancho y de 2.5-4 mm de grueso cerca de la base, ápice redondeado, mucronado, margen entero, generalmente con una línea de color rojo, base angosta formando un pseudopecíolo de $0.4-1 \mathrm{~cm}$ de longitud; inflorescencia 1-3 por roseta, en forma de panícula de $15-30 \mathrm{~cm}$ de alto incluyendo el pedúnculo, éste de 3-6 $\mathrm{mm}$ de diámetro cerca de la base, ramas 2-3 secundifloras con 1-7 flores cada una, brácteas dispuestas en espiral adpresas oblongo-obovadas, de 0.8-3 $\mathrm{cm}$ de largo, de 0.3-1.3 $\mathrm{cm}$ de ancho y de 0.15-4 mm de grueso en la parte media, de color verde ligeramente más claro que las hojas, contorno y mucrón de color rojo, base espolonada, deciduas; pedicelos de 3-8 $\mathrm{mm}$ de largo y cerca de $2 \mathrm{~mm}$ de diámetro; flor de $10-12 \mathrm{~mm}$ de largo, de cerca de $8 \mathrm{~mm}$ de diámetro cerca de la base; cáliz ligeramente extendido, sépalos fusionados en la base, extendidos en botón a algo adpresos en la antesis, oblongo-elípticos a lanceolados, desiguales de 4-9 $\mathrm{mm}$ de largo y de 2.5-3.5 $\mathrm{mm}$ de ancho y de 1-1.6 mm de grosor, tubo del cáliz de $1.5 \mathrm{~mm}$; corola conoide en botón, cilíndrico-urceolada o algo campanulada en la antesis, segmentos oblongolanceolados, de 10-11 $\mathrm{mm}$ de largo y $4 \mathrm{~mm}$ de ancho en la base, con una pequeña costilla en la parte media dorsal, de color rojo escarlata a rojo coral cerca de la base, ápice mucronado; estambres 10,5 opuestos a los pétalos, de 7 $\mathrm{mm}$ de largo, y 5 alternos de $8 \mathrm{~mm}$, anteras de $1.1 \mathrm{~mm}$ de largo; carpelos 5, libres, de $8 \mathrm{~mm}$ de alto y de 2.1 $\mathrm{mm}$ de ancho en la base; estilos de 3-4 $\mathrm{mm}$ de largo, de color rojo púrpura-marrón; folículos erectos, de $5 \mathrm{~mm}$ de largo; nectarios 5, de $0.5 \mathrm{~mm}$ de largo y $1.2 \mathrm{~mm}$ de ancho, amarillo pálido; semillas numerosas, de color café.

Material adicional examinado. México. Michoacán, municipio Nuevo Parangaricutiro, aproximadamente $1 \mathrm{~km}$ al norte de Nuevo San Juan Parangaricutiro. Alt. 1900 m; $19^{\circ} 25.38^{\prime \prime} \mathrm{N} ; 102^{\circ} 07.75^{\prime \prime}$ O. Bosque encino-pino. 10. X. 2007. I. García, Y. Hernández y M. García 7834 (CIMI, IEB, MEXU, ENCB, MICH).

Hábitat. Echeveria purhepecha crece sobre rocas de origen volcánico; ocasionalmente se ha observado epífita sobre Quercus spp. Sus poblaciones se desarrollan sobre rocas o en afloramientos rocosos en áreas protegidas o abiertas del bosque de encino-pino.

Distribución. Michoacán, México.

Fenología. Florece de septiembre a noviembre.

Etimología. El epíteto específico alude a la región geográfica de la etnia purhepecha, lugar en el que habita esta planta.

\section{Comentarios taxonómicos}

Considerando el razonamiento de Walther (1972), este taxón pertenece a la serie Retusae, aunque Moran (1974) fusiona Retusae y Gibbiflorae, reconoce sólo esta última. Kimnach (2003), Meyrán y López(2003) siguen este mismo criterio. En las plantas de la serie Retusae las estructuras morfológicas poseen un tallo corto pero evidente, simple o a veces estolonífero en la base, hojas numerosas agrupadas, o pocas y relativamente pequeñas, menores de $15 \mathrm{~cm}$ de largo y $7 \mathrm{~cm}$ de ancho, obtusas, retusas, agudas a veces estrechándose hacia la base, escasamente pecioladas, enteras a laceradas, verdes o glaucas o punteadas de rojo en el borde de la hoja; inflorescencia cima racemosa con 2-4 ramas o menos común simple o subpaniculada; pedúnculos generalmente robustos, erecto, con numerosas brácteas, anchas y delgadas; pedicelos evidentes, de $3 \mathrm{~mm}$ o más de largo; sépalos ascendentes o extendidos; corola de tamaño medio, raramente grande, escarlata o carmesí a coral o rojo-rosa, pétalos bruscamente quillado-despuntados, hundidos hacia la base, estilos oscuros, nectarios gruesos.

Se prefiere emplear el criterio de Walther (1972), quien separa este grupo (Retusae) en 2; el primero de hojas relativamente pecioladas, estrechas, 4 veces más largas que anchas y comúnmente con una línea roja en el borde de la hoja. El segundo grupo de hojas relativamente cortas y anchas, raramente 3 veces más largas que anchas. De esta última agrupación Kimnach (1998) separa E. obtusifolia Rose, considerándola una variante de E. fulgens Lem., "en virtud de una mayor afinidad y diferencias poco significativas, color verde de sus hojas y en el menor tamaño del tallo, hojas, tallo floral y sépalos" (Meyrán y López 2003).

En este sentido se considera que Echeveria purhepecha tiene mayor parecido con E. fulgens var. obtusifolia (Rose) Kimnach del segundo grupo, ya que presenta un tallo evidente, corto, hojas largas obtusas o retusas, color verde claro con el margen rojizo, inflorescencia ocasionalmente simple o de 2-3 ramas, pedicelos mayores a $4 \mathrm{~mm}$ de largo, hábitat y altitud en que se desarrollan; difiere en que $E$. purhepecha presenta hojas menos largas, longitud de la inflorescencia y número de flores por cincino menor, pedicelo y segmento mayor del cáliz más largo, corola rojo escarlata, segmentos de la corola oblongo-lanceolados (Cuadro 1).

\section{Agradecimientos}

Al Dr. Fernando Chiang (MEXU), por la diagnosis en latín, por sus sugerencias y revisión crítica; a los revisores anónimos, por sus comentarios y sugerencias; a Emmanuel Pérez Cálix (IEB), por sus valiosas aportaciones; a J. Antonio Machuca, por su auxilio en campo. Del CIIDIR-IPN Michoacán, a Ernesto Martínez, por su auxilio en la traducción del resumen; a Fabián 
Cuadro 1. Caracteres distintivos de Echeveria purhepecha y E. fulgens var. obtusifolia

$\begin{array}{lll}\text { Caracteres } & \text { E. purhepecha } & \text { E. fulgens var. obtusifolia }\end{array}$

\section{Tallo}

Largo $(\mathrm{cm})$

Diámetro $(\mathrm{cm})$

Núm. ramificaciones

Hojas:

Forma

Largo $(\mathrm{cm})$

Ancho (cm)

Inflorescencia

Largo $(\mathrm{cm})$

Núm. de ramas

Núm. de flores

por cincino

Brácteas:

Forma

Largo (cm)

Ancho (cm)

Pedicelo:

Largo $(\mathrm{cm})$

Segmentos del cáliz

Largo $(\mathrm{cm})$

Segmentos de la Corola

Largo (cm)

Color

Forma

Nectarios

Color

Tamaño $(\mathrm{cm})$

largo

ancho

Hábitat

Fenología (floración)

Distribución

\section{8-11}

hasta 1.2

2-4

oblongo-obovadas

2-6.5

$1-2.5$

15-30

2-3

$1-7$

oblongo-obovadas

0.8-3

0.3 a 1.3

$0.3-0.8$

$0.4-0.9$

1-1.2

rojo escarlata

oblongo-lanceolados

amarillo pálido

0.05

0.12

bosque de encino-pino

septiembre-noviembre

Michoacán
Hasta 15

simple o con 2-3

oblongo a obovadas-cuneadas

7.5-10

3-5

20-35

2-3

9-11

oblongas

2 (3.5?)

0.5

0.6 el mayor

1.3

rojo amarillento

agudos, extendidos hacia la punta

bosque de pino

septiembre?

Estado de México, Morelos y Michoacán 
Villalpando y Sigifredo López, por su auxilio en el manejo de las imágenes. A la COFAA del Instituto Politécnico Nacional por el apoyo para el desarrollo de estas investigaciones.

\section{Literatura citada}

Kimnach, M. 1998. New taxa and combinations in Echeveria (Crassulaceae). Haseltonia 5:51

Kimnach, M. 2003. Echeveria. In Illustrated handbook of succulent

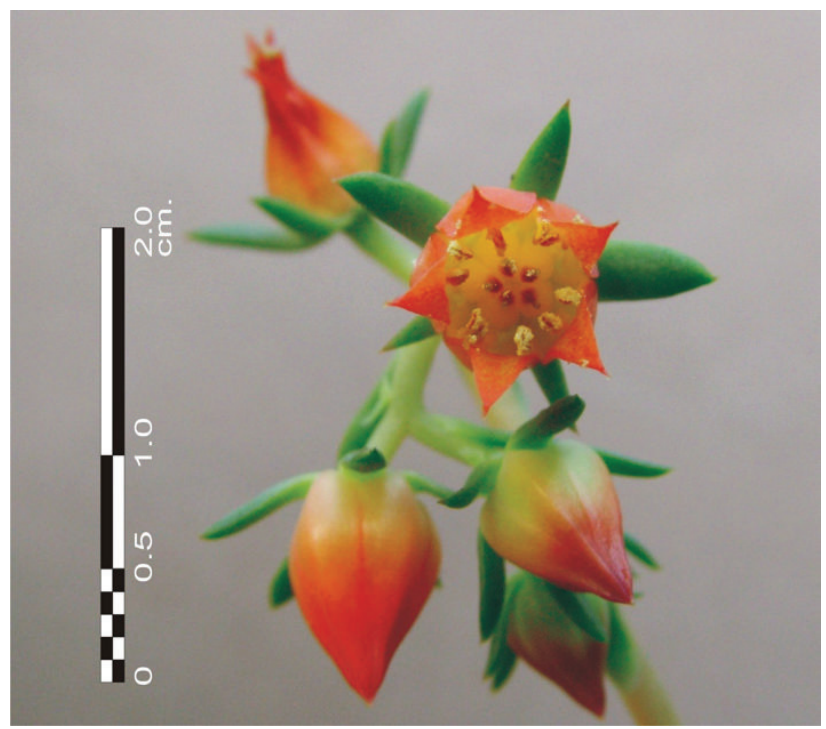

Figura 1. Inflorescencia de Echeveria purhepecha, que muestra el tamaño variable de los segmentos del cáliz, y la disposición de la corola, estambres y estilos.

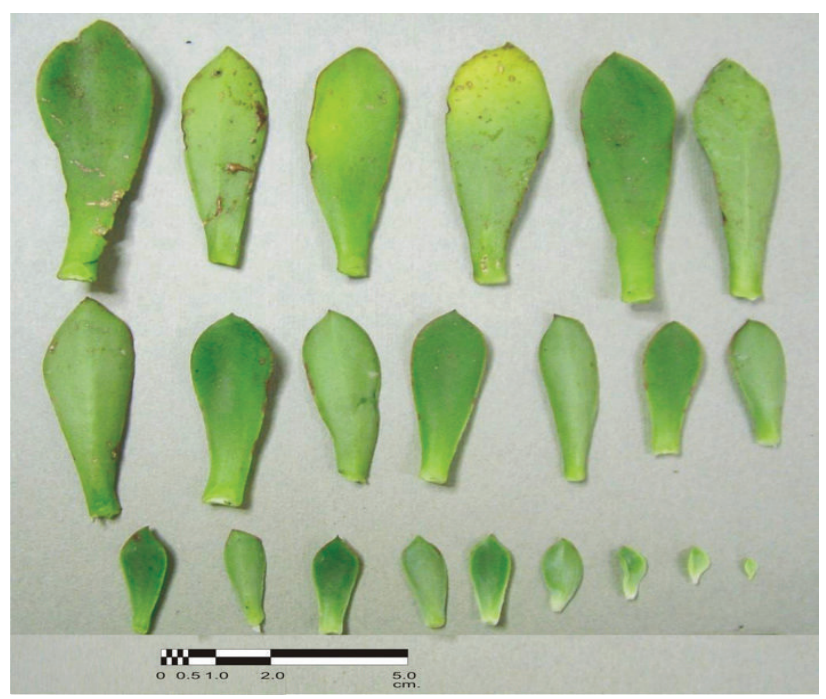

Figura 3. Variación en el tamaño y la forma de las hojas (primeras 2 hileras); variación en las brácteas de la inflorescencia (hilera inferior). plants: Crassulaceae, U. Eggli (ed.). Springer-Verlag, Berlin. p. 103-116.

Meyrán, J. y L. López. 2003. Las crasuláceas de México. Sociedad Mexicana de Cactología, México, D.F. 234 p. + láminas con fotografias.

Moran, R. 1974. Division of the genus Echeveria into series. In Lexicon of succulent plants, H. Jacobsen (ed.). Blandford, London. p. 184-186.

Walther, E. 1972. Echeveria. California Academy of Sciences, San Francisco. p.175-197.

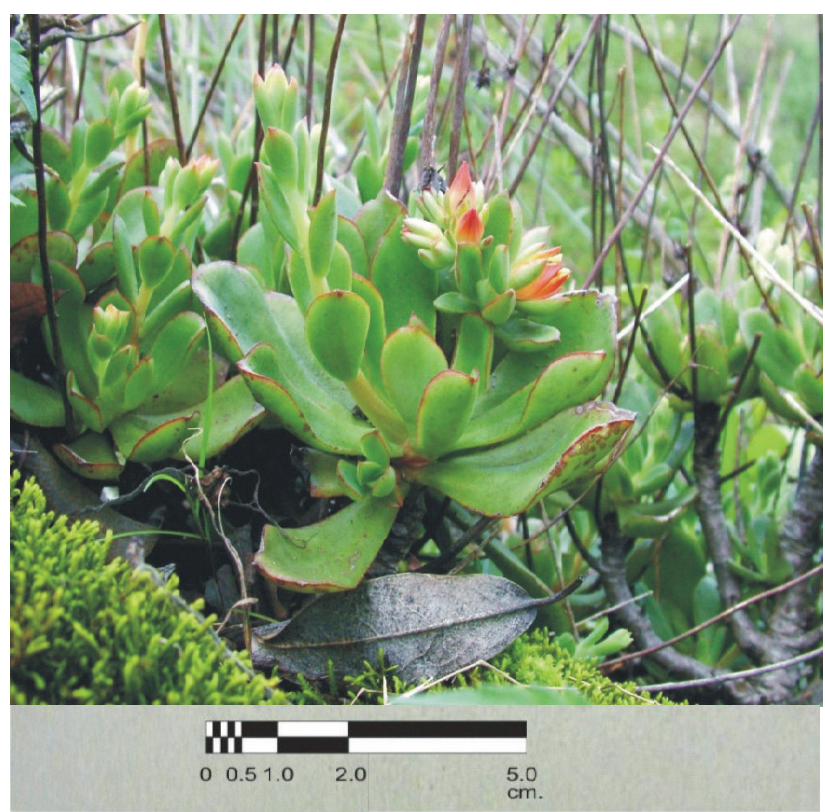

Figura 2. Echeveria purhepecha, hábito.

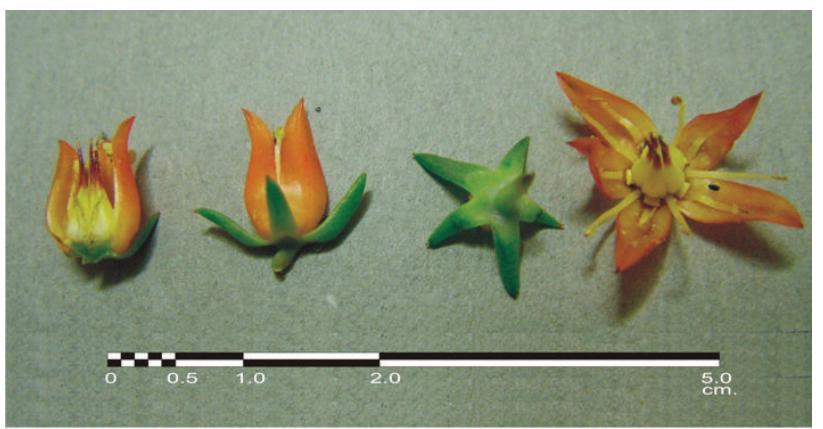

Figura 4. Segmentos del cáliz y de la corola de Echeveria purhepecha. 

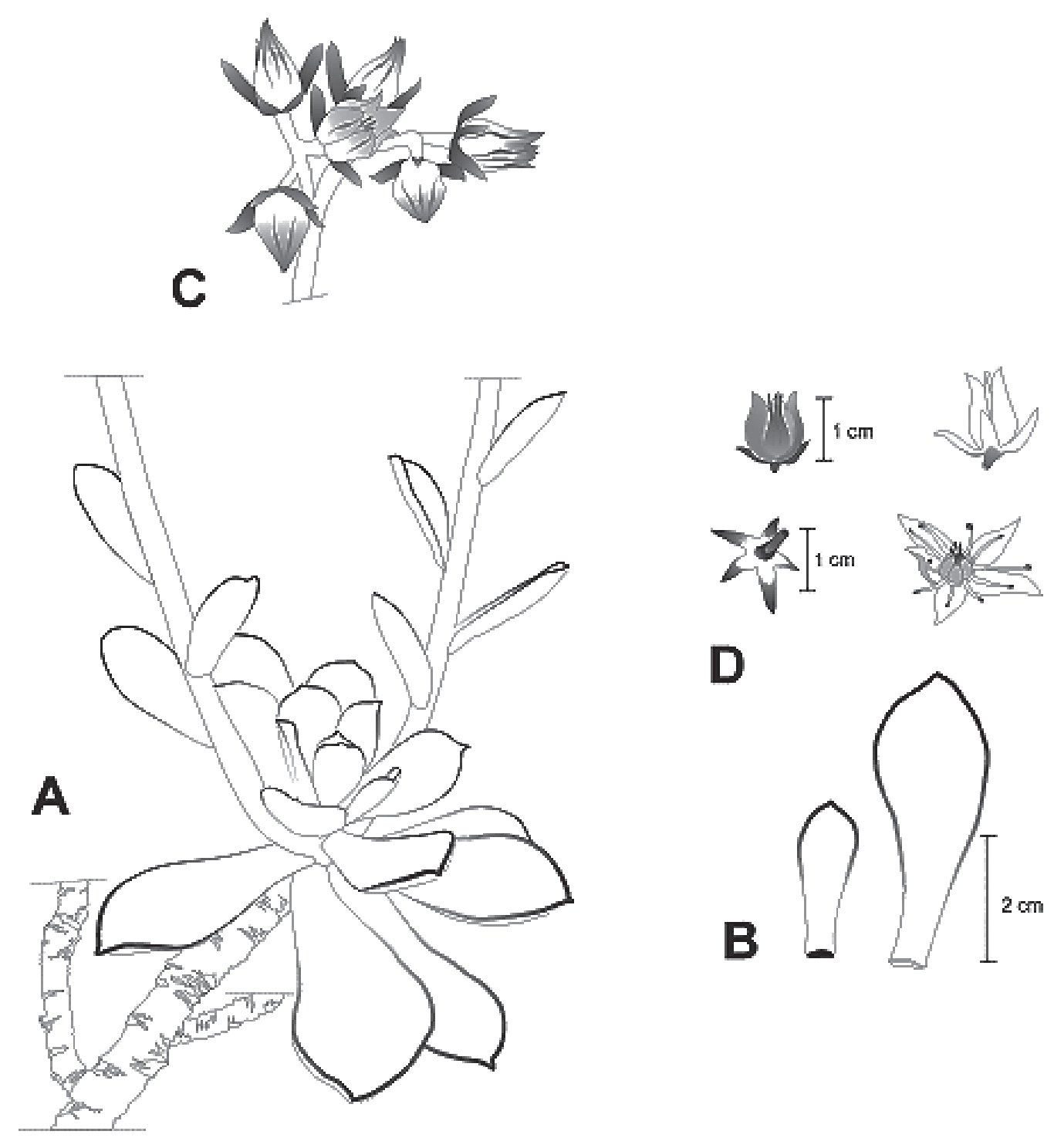

Figura 5. Echeveria purhepecha. A, hábito de la planta; B, láminas foliares; C, inflorescencia; D, perianto; cáliz, corola, gineceo y androceo (basado en I. García y J. A. Machuca 4491). 
